\title{
Structural and managerial cost differences in nonprofit nursing homes
}

\author{
L. Di Giorgio * $\quad$ M. Filippini ${ }^{\dagger} \quad$ G. Masiero ${ }^{\ddagger}$ \\ Published in Economic Modelling (2015), 51: 289-298, \\ http://dx.doi.org/10.1016/j.econmod.2015.08.015
}

\begin{abstract}
Population aging is challenging governments to find new solutions to finance the increasing demand for nursing home care and slow down the increase in expenditures. In this light, many European countries are currently considering reforms to increase efficiency in the provision of nursing home services. One popular restructuring policy is the transformation of public organizations into private nonprofit organizations. The underlying assumption is that private nonprofit nursing homes are more efficient than public nursing homes. However, there is limited empirical evidence to support this view. This analysis aims to contribute to the evidence base on this issue by investigating the impact of the organizational form on the costs of nursing homes. We use a sample of 45 nursing homes from one Swiss canton over a 5-year period (2001-2005). The applied estimation strategy provides more accurate estimates as compared to previous studies. In particular, we distinguish between cost differences that are under the control of the managers from those that are not (structural). Our findings suggest that public nursing homes are more costly than private nursing homes, although the difference is small. This cost difference is mainly driven by structural rather than managerial costs. Therefore, cost-reducing policies that promote private nonprofit nursing homes are expected to reduce costs only slightly.
\end{abstract}

Keywords: cost efficiency, nursing homes, nonprofit, ownership.

JEL classification: C23, I18, L20.

\footnotetext{
${ }^{*}$ Institute for Health Metrics and Evaluation (IHME), University of Washington, United States; Institute of Economics (IdEP), Università della Svizzera italiana (USI), Switzerland.

${ }^{\dagger}$ Institute of Economics (IdEP), Università della Svizzera italiana (USI); Department of Management, Technology and Economics, ETH Zurich, Switzerland.

${ }^{\ddagger}$ Department of Management, Information and Production Engineering, University of Bergamo, Italy; Institute of Economics (IdEP), Università della Svizzera italiana (USI), Switzerland. Corresponding author. E-mail address: giuliano.masiero@unibg.it.
} 


\section{Introduction}

The influence of different organizational (institutional) forms on nursing home $(\mathrm{NH})$ costs is a relevant issue in most health care systems. The institutional form affects the structural and managerial costs of NHs. Therefore, some institutional forms may prove to be more successful than others in providing cost-efficient services. Evidence regarding the impact of institutional forms on costs can inform policy-makers regarding preferred modes of delivering services to the elderly population.

In the last decade, different restructuring policies have been implemented to control public health expenditures, such as bed downsizing in hospitals (Piacenza et al., 2010). In the provision of nursing home services, a focus of restructuring policies has been the transformation of public NHs into private nonprofit (NFP) NHs. However, little evidence exists on differences in cost efficiency between institutional forms that support these policies.

This study aims to provide evidence on the impact of the institutional form on $\mathrm{NH}$ costs by exploring data from a region of Switzerland, the canton of Ticino. Because of high heterogeneity in the regulation and definition of nursing home services across countries, the investigation of differences in cost efficiency between institutional forms can be better conducted by focusing on relatively homogeneous areas. Also, the tight and heterogeneous regulation of long-term care across regions or countries generally implies a limited access to detailed and comparable data on costs of different organizational structures. Switzerland represents an ideal setting for our investigation since $\mathrm{NH}$ services are mostly provided by regulated nonprofit firms, and the country exhibits an almost perfect balance between private and public organizations. However, Switzerland is a federal country made of 26 cantons (states) with remarkable differences in terms of healthcare organization. Cantons have large autonomy in the provision and regulation of nursing home care. This leads to large heterogeneity in the organization of the supply. Therefore, the focus on one Swiss canton offers important advantages in terms of precision of cost data and their comparability 
between institutional forms.

The literature on cost efficiency of NHs has mainly focused on the effect of the ownership rather than the institutional form (e.g., Chou, 2002; Santerre and Vernon, 2005; Grabowski et al., 2009). To our knowledge, only a few studies analyze the impact of the institutional form (e.g., Holmes, 1996; Vitaliano and Torren, 1994). Two of them use Swiss data (Farsi and Filippini, 2004; Farsi et al., 2008) but do not distinguish between different types of efficiency.

In this study, we distinguish between structural and managerial cost differences to explain the mixed results found in previous analyses. Managerial cost differences reflect the ability of the managers to run a facility and can be expected to vary over time. Structural differences are constant features that are beyond the control of the managers, and may result from different production processes that characterize institutional forms. For instance, we think of political constraints, labor contracts, governance procedures, the location of NHs, and constraints in the choice of residents. We propose an empirical strategy to investigate the presence of both types of cost differences between public and private organizations.

The remainder of the paper is organized as follows: In section 2 we briefly discuss the related literature on structural and managerial differences between NFP organizations providing nursing home services. In section 3 we define different institutional forms in $\mathrm{NH}$ care and describe our setting. Then, in section 3.1, we sketch a theoretical model to derive hypotheses on the impact of managerial behavior and institutional aspects on cost efficiency. In section 4 we present our econometric approach to compare cost efficiency across different institutional forms, and we discuss the results. Section 5 is the conclusion.

\section{Related literature}

Kapur and Weisbrod (2000) recognize that government and private NFP firms do differ in their objective functions. Theoretical work points at different reasons why public and private NFP organizations may differ. The decision-making process in NHs varies across organizational forms, for instance because of differ- 
ent legal constraints or political pressure. Hart et al. (1997) see public managers as being constrained by some governments' agreement to implement any cost innovation decision while managers of private NFP firms can freely implement these decisions. In addition, these firms are expected to face lower probability of being bailed out by public authorities or tougher punishment for poor managerial effort. Differences in the institutional form may then lead to differences in $\mathrm{NH}$ efficiency.

From an empirical perspective, the issue of the institutional form in the $\mathrm{NH}$ sector has been partially addressed in the economic literature. The focus has mainly been on the effect of the ownership form by comparing for-profit to NFP organizations. Government-run organizations have typically been excluded from the analyses due to the small presence of public facilities in the US or due to the expectation that government NHs behave in a very different way than for-profit and NFP organizations (Grabowski et al., 2013). These studies show that forprofit NHs are less costly per client than NFP NHs but provide lower-quality services (Hillmer et al., 2005; Knox et al., 2002; O'Neill et al., 2003; Schlesinger and Grey, 2006). However, there is lack of empirical evidence on differences between public and private NFP organizations.

To our knowledge, only a few studies empirically analyze the impact of the institutional form on the performance of NFP NHs, with mixed results. Farsi and Filippini (2004) estimate inefficiency using the Schmidt and Sicklers (1984) random effects (RE) model on Swiss data. The authors show that private NHs are more efficient than public NHs. The study has two main drawbacks. First, inefficiency is assumed to be constant over time, and cost differences that change over time are captured by the error terms. Given the length of the panel, the assumption of time-invariant inefficiency may not be appropriate. Second, the results can be biased in the presence of unobserved factors that remain constant over time since the individual effects are interpreted as inefficiency. To address these limitations, Farsi et al. (2008) apply a true random effect model (TRE). This model allows for time-varying inefficiency and controls for unobserved heterogeneity with the individual effects. Therefore, time-invariant cost 
differences are interpreted as heterogeneity. The authors do not find evidence of significant differences between institutional forms. However, the authors only capture inefficiency that varies over time. Constant inefficiency is captured by the individual effects rather than being included in the traditional inefficiency term. This may lead to imprecise results if part of the inefficiency is due to features that do not change over time.

With respect to previous Swiss studies, the novelties of this paper are two. First, we propose an empirical strategy that provides information on efficiency due to structural differences related to the institutional form. Second, we sketch a theoretical model to disentangle the impact of institutional aspects from the behavior of managers on cost efficiency.

\section{Institutional forms in nursing home care}

According to the ownership type, NFP NHs are usually categorized into public and private NHs. Although these types are supposed to reflect differences in the control of funds and the production process, the classification may not effectively capture differences in the organizational form. A more sophisticated insight looks at the institutional form, which underlines property rights or legal constraints affecting different institutions. Hence, public-law NHs are public administrative units without a separate juridical status from the local public administration and are directly integrated into it. The governing body is represented by local politicians (city council), while the executive arm is left to the municipality, which delegates it to a manager. Conversely, private-law NFP NHs usually take the form of a foundation. Generally, foundations are created by individuals or private legal entities. In some cases, local governments decide to create private-law NFP NHs. Therefore, when local governments set up a foundation to provide nursing home services, this is a private-law institution owned by the government. In both of these cases the governing body is the foundation council.

These institutional types apply to Switzerland where the provision of $\mathrm{NH}$ services is dominated by NFP institutions regulated at cantonal (state) level. 
In some cantons the provision is further decentralized at the municipality level. In this case, each NH provides care to the residents of a given area. The choice of the NH does not depend on price and quality aspects since individuals are usually assigned to the $\mathrm{NH}$ in the former place of residence. Therefore, NHs generally operate as local monopolies, i.e. clients have no choice of NH. Prices are subsidized by the cantonal regulator, leading to excess demand and waiting lists. In the Swiss Canton of Ticino, where we focus this analysis, around $51 \%$ of NFP NHs are private-law organizations, and $49 \%$ are public-law organizations.

\subsection{A theoretical approach}

We assume that low managerial effort translates into low efficiency levels of $\mathrm{NH}$ care. ${ }^{1}$ The total costs of the $\mathrm{NH}$ are described by the following equation:

$$
\tilde{C}=\tilde{\theta}-g(e),
$$

where $\tilde{\theta}$ defines costs that are independent of managerial effort, $e$. $\tilde{\theta}$ is a random variable that takes value $\underline{\theta}$ with probability $q_{z}$ and $\bar{\theta}$ with probability $\left(1-q_{z}\right)$, with $\bar{\theta}>\underline{\theta}$. The subscript $z$ indicates the institutional form, i.e. public-law $(P u)$ or private-law NFP $(P r)$. $\tilde{\theta}$ depends, for instance, on political constraints, labor contracts, procedures, the location of the $\mathrm{NH}$, and the mix of residents which are regulated by the law. $g(e)$ is a function that measures the impact of manager's effort on costs. This depends on the difference between the benefit of effort for the $\mathrm{NH}$ in terms of cost reduction, $\rho(e)$, and the cost of remunerating manager's effort through an increase in the wage. Hence, manager's effort reduces total cost but may imply a higher wage, $w_{z}(e)$. Generally, the benefit of effort for the $\mathrm{NH}$ offsets the cost of remunerating manager's effort. Therefore, the net effect of effort is expected to be a reduction in costs, i.e. $g(e)>0$. To simplify the analysis, we assume $g(e)=\rho(e)-w_{z}(e)=e .^{2}$

The regulator cannot directly observe the NH-specific $\theta$ and $e$. The true value of $\theta$ and the optimal level of effort to reduce costs can be inferred from the

\footnotetext{
${ }^{1}$ This approach is inspired by the early work of Haskel and Sanchis (1995), among others.

${ }^{2}$ The level of effort $e$ is assumed to be bound in the interval $e \in\left[0, e_{\max }\right]$, where $e_{\max }=$ $q_{z}(\bar{\theta}-\underline{\theta})$. This interval is known to the regulator and ensures that NHs with high $\operatorname{costs}(\tilde{\theta}=\bar{\theta})$ can never move costs down the low cost level $(\tilde{\theta}=\underline{\theta})$.
} 
observation of total costs $C$ reported by the $\mathrm{NH}$, which are then used to define the financial budget. Consequently, the financial budget is defined as:

$$
B \equiv E(\tilde{C} \mid C)
$$

The governing board of the NH has the following utility function which is separable into patients' benefits $(s)$ and firm's profits $(\pi)$ :

$$
U_{z}=\alpha_{z} \pi+\left(1-\alpha_{z}\right) s
$$

$\alpha_{z} \in(0,1)$ captures institutional preferences that affect the relative importance of profits with respect to patients' benefits. For example, the board of a public-law NH may value the preferences of the whole voters' community while a private-law NFP board may value those of the donors or of particular groups of interest. These organizational constraints may not be flexible in the short run and may not be directly controlled by the manager. They generally require actions to be approved by the board.

Profits are defined as $\pi(e) \equiv B-\tilde{C}(e)$ and the manager's utility is given by the following expression:

$$
U_{m}=\left[w_{z}(e)-\phi(e)\right]+\gamma_{m} U_{z}(\pi(e))
$$

where $\phi(e)$ is disutility of effort and $\gamma_{m} \in(0,1)$ is the manager's share of the goals of the board. The manager's utility is additive in effort and the degree of sharing of the board's objectives, with $w_{z}^{\prime}(e) \geq 0, w_{z}^{\prime \prime}(e) \leq 0, \phi^{\prime}(e)>0$ and $\phi^{\prime \prime}(e)>0$. For simplicity, the reservation utility is assumed to be zero so that the participation constraint of the manager is always satisfied for any level of the wage.

\subsubsection{Cost reduction effort}

The optimal choice of effort for the manager is obtained from the first-order condition to maximize Eq. (4). We first substitute Eq. (1) and Eq. (2) into Eq. (3). Using Eq. (3) we then replace $U_{z}$ in Eq. (4), and finally differentiate Eq. (4) for the level of effort to get $d U_{m} / d e=0$. Solving the first-order condition 
for $e$ we get the equilibrium level of effort as: ${ }^{3}$

$$
\phi^{\prime}\left(e^{*}\right)=w_{z}^{\prime}\left(e^{*}\right)+\alpha_{z} \gamma_{m}
$$

In equilibrium the marginal cost of effort is equal to the marginal benefit of effort. The marginal benefit of effort can be decomposed into two parts: the marginal effect of effort on wage, $w_{z}^{\prime}\left(e^{*}\right)$, and the "altruistic" component $\alpha_{z} \gamma_{m}$. The latter component includes cost-reduction effort due to manager's type $\left(\gamma_{m}\right)$ and cost-reduction effort due to structural differences by institutional form $\left(\alpha_{z}\right)$. Higher levels of effort in equilibrium derive from higher incentives in the wage structure, higher degrees of goal sharing $\left(\gamma_{m}\right)$, and weaker preferences for patients' benefits $\left(\alpha_{z}\right)$. Also, $\alpha_{P u}<\alpha_{P r}$ and $w_{P u}^{\prime}\left(e^{*}\right) \leq w_{P r}^{\prime}\left(e^{*}\right)$ if public boards put more weight on community benefits rather than profitability and tend to compensate managers less for their effort. ${ }^{4}$ The degree to which managers working in private-law NFP NHs share the objectives of the council is expected to be higher than, or at least equal to, that of managers working in public NHs. This statement relies on factors suggested by different authors in the literature (Rose-Ackerman, 1996; Wilson, 1989). Managers working in foundations are expected to be more likely to be driven by altruistic motives and to be punished in case of poor performance, and are less likely to follow multiple objectives with which they may not agree.

\subsubsection{Structural and managerial inefficiency}

To analyze differences in costs between NH types we can decompose deviations of $\mathrm{NH}$ costs from total mean costs into deviations between groups (institutional

\footnotetext{
${ }^{3}$ Note that the $\mathrm{NH}$ always reveals its true type. Assume that the disutility of effort takes the form $\phi(e)=\frac{e^{2}}{2}$, and the manager's wage is $w(e)=\beta+\eta_{z} e$; hence $e^{*}=\eta_{z}+\alpha_{z} \gamma_{m}$. For $C>\underline{\theta}$, the regulator can infer that the $\mathrm{NH}$ is a high-cost type. The regulator sets $B_{z}=\bar{\theta}-\bar{E}\left(e_{z}\right)=\bar{\theta}-q_{z}(\bar{\theta}-\underline{\theta}) / 2$ (see footnote 2 ) and the NH makes profits provided that $q_{z}(\bar{\theta}-\underline{\theta}) / 2<\eta_{z}+\alpha_{z} \gamma_{m}$. Conversely, for $C \leq \underline{\theta}$ the regulator correctly infers that the NH is a low-cost type since $C=\bar{\theta}-e_{\max }>\underline{\theta}$. Hence, $B_{z}=\underline{\theta}-E\left(e_{z}\right)=\underline{\theta}-q_{z}(\bar{\theta}-\underline{\theta}) / 2$. Again NHs make profits for levels of effort $q_{z}(\bar{\theta}-\underline{\theta}) / 2<\eta_{z}+\alpha_{z} \gamma_{m}$.

${ }^{4}$ In the past, the public administration was not able to link the performance of the manager directly to the level of the salary. Nowadays, the introduction of New Public Management instruments allows for this link with some restrictions.
} 
forms) and deviations within groups. Therefore, we can decompose cost deviations into structural (institutional) and managerial components.

We assume that there is an equal number of public-law and private-law NHs in the market. Therefore, looking at the equilibrium level of cost reduction, we can disentangle the institutional component from the NH-specific managerial component:

$$
e^{*}-\hat{e}^{*}=\left(e^{*}-\hat{e}_{z}^{*}\right)+\left(\hat{e}_{z}^{*}-\hat{e}^{*}\right)
$$

where $\hat{e}^{*}$ is the mean cost reduction across institutional forms and $\hat{e}_{z}^{*}$ is the mean cost reduction within the same institutional form. The term $\hat{e}_{z}^{*}-\hat{e}^{*}$ represents deviations from the mean cost reduction due to institutional-specific features $(z)$, and $e^{*}-\hat{e}_{z}^{*}$ represents deviations from the institutional-specific cost reduction because of managerial effort.

Assuming $\phi(e)=\frac{e^{2}}{2}$ and $w_{z}(e)=\beta+\eta_{z} e$ and substituting into Eq. (6) we get:

$$
\begin{aligned}
e^{*}-\hat{e}^{*} & =\left[\left(\eta_{z}+\alpha_{z} \gamma_{m}\right)-\left(\eta_{z}+\alpha_{z} \hat{\gamma}_{z}\right)\right]+\left[\left(\eta_{z}+\alpha_{z} \hat{\gamma}_{z}\right)-(\hat{\eta}+\hat{\alpha} \hat{\gamma})\right] \\
& =\alpha_{z}\left(\gamma_{m}-\hat{\gamma}_{z}\right)+\left[\left(\eta_{z}+\alpha_{z} \hat{\gamma}_{z}\right)-(\hat{\eta}+\hat{\alpha} \hat{\gamma})\right]
\end{aligned}
$$

where $\hat{\gamma}=\sum_{z=P r, P u} \hat{\gamma}_{z} / 2, \hat{\eta}=\sum_{z=P r, P u} \eta_{z} / 2$, and $\hat{\alpha}=\sum_{z=P r, P u} \alpha_{z} / 2$ are means between groups, and $\hat{\gamma}_{z}=\sum_{m} \gamma_{m z}$ is the within-group mean. If the distribution of managerial characteristics is the same across institutional types, then $\hat{\gamma}=\hat{\gamma}_{z}$. Hence, $\left[\left(\eta_{z}+\alpha_{z} \hat{\gamma}_{z}\right)-(\hat{\eta}+\hat{\alpha} \hat{\gamma})\right]=\left(\eta_{z}-\hat{\eta}\right)+\hat{\gamma}_{z}\left(\alpha_{z}-\hat{\alpha}\right)$ is the difference in cost reduction due to NH institutional features, and $\alpha_{z}\left(\gamma_{m}-\hat{\gamma}_{z}\right)$ is the difference in cost reduction due to $\mathrm{NH}$-specific managerial characteristics.

Using (7) and assuming $\hat{\gamma}=\hat{\gamma}_{z}$, we can write total deviations from mean costs as:

$$
\begin{aligned}
\tilde{C}-\hat{C} & =\left(\tilde{\theta}-e^{*}\right)-\left(\hat{\theta}-\hat{e}^{*}\right) \\
& =\left[\left(\tilde{\theta}-\hat{\theta}_{z}\right)+\left(\hat{\theta}_{z}-\hat{\theta}\right)\right]+\alpha_{z}\left(\hat{\gamma}_{z}-\gamma_{m}\right)+\left[\left(\hat{\eta}-\eta_{z}\right)+\hat{\gamma}_{z}\left(\hat{\alpha}-\alpha_{z}\right)\right] .
\end{aligned}
$$

In the above equation, $(\tilde{\theta}-\hat{\theta})$ are deviations from average structural costs that cannot be controlled by the institution, and $\hat{\theta}=\sum_{z=P r, P u}\left[q_{z} \underline{\theta}+\left(1-q_{z}\right) \bar{\theta}\right] / 2$ 
are average structural costs over all institutional types. These deviations can be decomposed into a firm-specific component $\left(\tilde{\theta}-\hat{\theta}_{z}\right)$ and deviations from institutional form-specific structural $\operatorname{costs}\left(\hat{\theta}_{z}-\hat{\theta}\right)$, where $\hat{\theta}_{z}=q_{z} \underline{\theta}+\left(1-q_{z}\right) \bar{\theta}$. The other differences in costs across NHs can be decomposed into a managerial component and another structural component controlled by the institutional form. The former component is captured by $\alpha_{z}\left(\hat{\gamma}_{z}-\gamma_{m}\right)$. The latter component is defined by the term $\left[\left(\hat{\eta}-\eta_{z}\right)+\hat{\gamma}_{z}\left(\hat{\alpha}-\alpha_{z}\right)\right]$. Differences in costs due to institutional constraints can then be separated from other NH-specific (managerial) aspects. Note that only part of the (structural) costs due to the institutional form are exogenous. The remaining part of the structural costs are generated by institutional aspects that affect the behavior of managers.

To disentangle the managerial and the structural cost components and compare efficiency levels between public-law and private-law NHs, we propose an empirical approach. This is based on the specification of a cost function, which is then estimated on the whole population of public-law and private-law NFP NHs from the Swiss canton of Ticino. As we will discuss later in detail, the two structural components and the managerial component included in Eq. (8) are measured by different terms in the empirical cost model specification.

Note that our theoretical model assumes that the regulator can observe the institutional form as well as the true type of the NH. Consequently, the regulator can assign different budgets not only to different $\mathrm{NH}$ types of the same institutional form, but also to different institutional forms. Hence, the structural cost component can be separated from the managerial component. The empirical approach that follows actually try to disentangle these two components. A similar approach could be applied by the regulator using available cost data. This will provide a measure of different types of inefficiency and, therefore, could be used to refine the budget. 


\section{The empirical analysis}

\subsection{Efficiency measurement}

In order to estimate the level of overall productive efficiency it is possible to use parametric and non-parametric frontier analysis. In non-parametric approaches, like Data Envelopment Analysis (DEA), the production or cost frontier is considered as a deterministic function of the observed variables. Conversely, in parametric approaches, such as Stochastic Frontier Analysis (SFA), the production or cost frontier is estimated using econometric methods. ${ }^{5}$

The major merit of DEA is that the approach does not impose a priori parametric restrictions on the functional form of the cost frontier, nor does it rely on distributional assumptions of the error term to identify the efficiency. However, DEA is deterministic and therefore does not account for measurement error. On the other hand, SFA specifies an econometric model for the cost frontier and assigns part of the deviation from the frontier to measurement error in the data. SFA also embeds the traditional statistical properties which can be used to guide the model specification, while this is not possible in DEA. Further, parametric methods are more attractive to analyze the level of cost efficiency in the nursing home sector, because they allow us to deal, at least partially, with the presence of unobserved heterogeneity in the production of health care services. Finally, SFA resorts to economic theory to define the cost frontier, rather than being guided by the data only. For these reasons, SFA is our preferred approach.

The underlying idea of SFA is to use the residual to gather information regarding inefficiency. The residual $\varepsilon_{i}$ captures the deviation of both measurement error and inefficiency. SFA focuses on techniques to separate the two components. These techniques are based on the assumption that the two error components follow different distributions: the random component is assumed to be normally distributed, while inefficiency is assumed to be right-skewed. SFA models can be distinguished in models for cross-sectional data and models for

\footnotetext{
${ }^{5}$ See, for instance, Kumbhakar and Lovell (2003) and Murillo-Zamorano (2004) for a general presentation of different methodologies.
} 
panel data. Panel data models were first introduced by Pitt and Lee (1981) and Schmidt and Sickles (1984), who interpreted the firm-specific effect as inefficiency. In the following years models were extended to allow efficiency to change over time (e.g., Battese and Coelli, 1992; Cornwell et al., 1990; Sickles, 2005), though inefficiency and time-invariant unobserved heterogeneity could never be disentangled. Unobserved heterogeneity captures characteristics of the NHs such as location or catchment population that affect their costs but are not under the control of the firm, and therefore should not be attributed to inefficient behavior.

The recently developed True Random effect (TRE) and True Fixed effect (TFE) models proposed by Greene (2005) are an alternative to the panel data models proposed by Pitt and Lee (1981) and Schmidt and Sickels (1984). In the TRE and TFE models the original stochastic frontier model proposed by Aigner et al. (1977) is extended by adding fixed and random individual effects, respectively. The TRE and TFE produce values of the level of efficiency that vary over time (transient). In these models the individual fixed or random effects take into account all unobserved variables that are time invariant. Therefore, in these models any time-invariant (persistent) component of inefficiency is completely absorbed in the firm-specific constant terms. When the production of health care services is characterized by a structurally inefficient use of inputs, these models will produce relatively high levels of estimated cost efficiency. ${ }^{6}$ For the current analysis we use TRE rather than TFE due to the convergence issues encountered with the TFE model. As we will discuss later, we are able to disentangle structural cost differences from time-varying inefficiency by introducing a dummy variable for the institutional form in our cost model.

\footnotetext{
${ }^{6}$ Note that some scholars have recently proposed an extension of the TRE model, the generalized TRE model that allows for the possibility of estimating the level of persistent and transient efficiency of an economic agent at the same time. See, for instance, Colombi et al. (2014) and Filippini and Greene (2015).
} 


\subsection{Detailing the cost function}

SFA has been applied to assess the performance of very diverse industries (e.g., Castiglione and Infante, 2014; Charoenrat and Harvie, 2014; Danquah and Ouattara, 2015). Our cost function assumes that NHs transform three inputs capital, labor and material - into a single output, measured by the number of patient-days of nursing care. ${ }^{7}$ A similar specification is used by Di Giorgio et al. (2014) to investigate the effects of a change in the payment system using a cost-regression approach.

We rule out strategic interactions among NHs and their effect on the demand of residents since NHs are local monopolies. The number of patient-days can be considered a good indicator of the level of production after controlling for differences in quality. The total costs function depends on output $(Y)$, the prices of labor, capital and material $\left(P_{l}, P_{k}, P_{m}\right)$, two output characteristics $\left(Q_{1}, Q_{2}\right)$, a dummy variable $(Z)$ which takes value equal to 1 for public $\mathrm{NHs}$ and 0 otherwise, and time dummies for the years 2002-2005 $(\tau)$ which should capture technological progress in each year: ${ }^{8}$

$$
C=f\left(Y, P_{l}, P_{k}, P_{m}, Q_{1}, Q_{2}, Z, \tau\right)
$$

The price of labor is calculated as the weighted average wage of different professional categories employed in the NH (doctors, nurses, administrative, and technical staff) to avoid multicollinearity problems that may arise with labor prices for different categories. The amount of staff as well as their certification is defined by the cantonal law as a function of residents' case-mix. This rules out the possibility of increasing cost efficiency by hiring lower certified nurses. ${ }^{9}$

\footnotetext{
${ }^{7}$ Output and input prices are assumed to be exogenous. Output is exogenous because NHs have to accept all residents in a given area. The price of labor is defined by labor contracts at the cantonal level, which are equal for all NHs in the sample. Also, the same amortization schedule and interest rates are applied.

${ }^{8}$ In a non-competitive environment such as the Swiss one, there is no reason to assume that NHs minimize costs. In this case, the estimated cost function is a "behavioral cost function" (Evans, 1971) and can still be used to make a comparison among firms. Moreover, by estimating a total costs function instead of a variable costs function we avoid the risk related to a possible high correlation between capital stock and output leading to a positive relationship between variable cost and capital stock (Filippini, 1996).

${ }^{9}$ The monetary compensation of the staff is also a function of age. Therefore, there exists
} 
The price of capital is calculated as the sum of mortgage costs, amortization, and costs related to capital purchases divided by the capital stock, which is approximated by the number of beds. The price for material is computed by taking the remaining costs and dividing them by the number of meals provided each year. This item mainly includes costs for food and residency. Other costs included are energy, water and administrative costs.

Additionally, we control for some output characteristics that may explain cost differences across NHs. ${ }^{10} Q_{1}$ is an index which measures average patient assistance by means of normal daily activities such as eating, personal care or physiological activities. This is calculated on a yearly basis by the Regional Department of Public Health (RDPH). Patients are classified in one out of five categories according to their severity level. Each patient is assigned a value between 0 and 4, where higher values indicate more severe cases.

$Q_{2}$ is the nursing staff ratio, that is the ratio between the number of nurses employed and the number of nurses that should be employed according to the guidelines of the RDPH (optimal amount of staff). ${ }^{11}$ Because nursing care is a labor-intensive service, staffing level has been recognized as a good indicator for quality. ${ }^{12}$ Consequently, the nursing staff ratio is regulated by the RDPH. To avoid worsening quality, NHs are not allowed to deviate from the suggested number of nurses by more than $\pm 10 \%$. Since labor cost represents the major cost of production (cfr. section 3.2), a small change in the nursing staff ratio may affect total cost considerably. For this reason, NHs with high costs may decide to decrease the proportion of workers. On the other hand, efficient NHs may hire new workers or increase the working time in order to justify additional

the possibility of reducing costs by hiring younger staff members. Due to lack of data, we cannot rule out this strategy.

${ }^{10}$ In order to estimate a cost function, either the output is assumed to be homogenous or we need to control for service intensity and patients' characteristics (Birnbaum et al., 1981).

${ }^{11}$ As compared to other quality indicators related to staff levels, our indicator is conceptually different. The nursing staff ratio is the deviation from the optimal number of nurses that should be employed according to guidelines rather than the number of staff nurses actually employed.

${ }^{12}$ In a recent review, Bostick et al (2006) show a positive association between staffing levels and quality of care, and the link between staffing levels and direct indicators of quality, such as functional ability, pressure ulcers and weight loss. 
costs to the regulatory authority. The endogeneity of the nursing staff ratio is confirmed by the robust Durbin-Wu-Hausman test performed using the lagged $Q_{2}$ as instrumental variable (Cameron and Trivedi, 2005). The null hypothesis of exogenous $Q_{2}$ is rejected at any standard levels of significance. To address the endogeneity problem, lagged values of the nursing staff ratio are used. ${ }^{13}$ Given that $Q_{2}$ is determined during the operating year (for example through flexible working time) while the budget is defined at the beginning of the year, the lagged value of $Q_{2}$ is expected to be a valid instrument. ${ }^{14}$

The dummy variable $Z$ captures structural cost differences across institutional forms. This variable can be assumed to be exogenous for two main reasons. First, organizational form differences are mainly driven by historical reasons. Precisely, nursing home care was initially provided by religious foundations. Later, increasing demand for nursing home care and lack of supply led local governments to build new NHs. Second, NHs changing institutional form are not allowed to benefit from financial advantages.

In order to impose as few restrictions as possible, we adopt a flexible translog functional form approximated at the median value, a less sensitive statistic to outliers than the mean. ${ }^{15}$ Input prices and total costs are divided by the material price in order to satisfy the homogeneity condition in input prices. ${ }^{16}$ The

\footnotetext{
${ }^{13}$ This is a rather simple approach to tackle endogeneity in frontier analysis where other classical solutions, such as two-stage least-squares, are not completely satisfactory. See Greene (2010) for a detailed discussion on endogeneity issues in frontier models.

${ }^{14}$ The output of the test statistic on the endogeneity of $Q_{2}$ is: $F(1,44)=11.52(p=0.002)$. The endogeneity test is performed on the cost model with first order coefficients. The statistics provided give some evidence that the lagged value is a valid instrument. The first stage regression summary indicates that the lagged value explains $40 \%$ of the variability in $Q_{2}$. The Stock and Yogo test at 5\% level of tolerance greatly rejects the null hypothesis of weak instrument $(\mathrm{F}=80.57>16.38)$. The same analysis performed on the two-years lagged value of $Q_{2}$ suggests that this instrument is likely to be weak.

${ }^{15}$ A flexible translog functional form is adopted, for instance, by Rosenbaum et al. (2001) to investigate the effects on costs of relocation of residents from NHs to less expensive assisted care facilities.

${ }^{16}$ The cost function is linear homogenous of degree 1 in input prices when a $10 \%$ increase in all input prices leads to a $10 \%$ increase in total cost.
} 
stochastic translog approximation to Eq. (9) for the TRE model is:

$$
\begin{aligned}
& \ln \left(\frac{C}{P_{m}}\right)=\delta_{0}+\delta_{Y} \ln Y+\delta_{Q_{1}} \ln Q_{1}+\delta_{Q_{2}} \ln Q_{2}+\delta_{P_{l}} \ln \frac{P_{l}}{P_{m}}+ \\
& +\delta_{P_{k}} \ln \frac{P_{k}}{P_{m}}+\frac{1}{2} \delta_{Y Y}(\ln Y)^{2}+\frac{1}{2} \delta_{Q_{1} Q_{1}}\left(\ln Q_{1}\right)^{2}+\frac{1}{2} \delta_{Q_{2} Q_{2}}\left(\ln Q_{2}\right)^{2}+ \\
& +\frac{1}{2} \delta_{P_{l} P_{l}}\left(\ln \frac{P_{l}}{P_{m}}\right)^{2}+\frac{1}{2} \delta_{P_{k} P_{k}}\left(\ln \frac{P_{k}}{P_{m}}\right)^{2}+\delta_{Y Q_{1}} \ln Y \ln Q_{1}+ \\
& +\delta_{Y Q_{2}} \ln Y \ln Q_{2}+\delta_{Y P_{l}} \ln Y \ln \frac{P_{l}}{P_{m}}+\delta_{Y P_{k}} \ln Y \ln \frac{P_{k}}{P_{m}}+ \\
& +\delta_{Q_{1} P_{l}} \ln Q_{1} \ln \frac{P_{l}}{P_{m}}+\delta_{Q_{1} P_{k}} \ln Q_{1} \ln \frac{P_{k}}{P_{m}}+\delta_{Q_{1} Q_{2}} \ln Q_{1} \ln Q_{2}+ \\
& +\delta_{P_{l} Q_{2}} \ln \frac{P_{l}}{P_{m}} \ln Q_{2}+\delta_{P_{k} Q_{2}} \ln \frac{P_{k}}{P_{m}} \ln Q_{2}+\delta_{P_{k} P_{l}} \ln \frac{P_{k}}{P_{m}} \ln \frac{P_{l}}{P_{m}}+ \\
& +\delta_{z} Z+\delta_{t} \tau+\varepsilon_{i t}+\alpha_{i},
\end{aligned}
$$

where $\varepsilon_{i t}=u_{i t}+v_{i t}$, with $u_{i t}$ being the time-varying inefficiency term assumed to be an iid random variable with half-normal distribution, that is a normal distribution truncated at zero. $v_{i t}$ is a stochastic component normally distributed, and $\alpha_{i}$ is an iid random component in a random-effects framework. The latter term should capture all time-invariant unobserved factors.

Table 1 summarizes the econometric specifications employed in this paper. Following the estimation of the parameters, we check the concavity condition in input prices.

\subsection{Data and descriptive statistics}

Our study exploits an unbalanced panel data set of $50 \mathrm{NHs}$ operating in a region of Switzerland (canton Ticino) over a five-year period (2001-2005). The focus on one Swiss canton is justified by a relatively high degree of homogeneity in the data, since data imputation processes and some regulatory aspects vary across cantons. Using data from 26 cantons with large differences in the organization and the regulation of health care services may undermine the comparability of the results across institutional forms. Finally, we can exploit some cantonalspecific information on costs that is not available at the federal level. Clearly, the period of time to study is limited. However, as compared to previous studies 
on Swiss NHs (e.g., Crivelli et al., 2002), our dataset includes full information on capital costs for public NHs that was not available before. ${ }^{17}$

All NHs in the sample are medicalized institutions (skilled NHs) under the cantonal nursing home planning. The cantonal planning defines daily rates, the minimum necessary infrastructure, and the amount and certification of staff based on residents' needs to ensure high-quality standards. It also defines supply capacity in terms of beds, and subsidies to public-law and private-law NFP NHs. Consequently, the production process is highly homogenous and comparable across NHs.

Data are extracted from annual reports delivered to the RDPH by regulated NHs. NHs with foyers are excluded from our sample. ${ }^{18}$ One NH shows unreasonable values, hence it is also excluded from the analysis. ${ }^{19}$ The final sample contains data on $45 \mathrm{NHs}, 22$ private-law NFP NHs and 21 public-law NHs, ${ }^{20}$ with a total number of observations equal to 215 . The number of observations used for estimation is 210 . This is due to the fact that we use the lagged value of $Q_{2}$ and for five NHs we do not have information for the year 2000.

Table 2 presents the summary statistics for the main costs and input variables of interest: mean, standard deviation, median, minimum and maximum values for our sample. All input prices, total cost and variable cost are inflated to 2005 constant currency units (Swiss francs) using the national Consumer Price Index. The average cost per resident day in the most expensive NH is almost twice the average cost of the least expensive home, with an average of about 233 Swiss francs (Sfr). This difference is at least partially explained by the large heterogeneity in NHs characteristics. In particular, facilities vary in

\footnotetext{
${ }^{17}$ These additional data on amortization costs of public NHs have been made available just recently.

${ }^{18}$ Foyers are external residential apartments where nursing care is provided to the most "inhealth" patients. Since the production process may differ substantially when a considerable share of patient-days is spent in foyers $(>10 \%)$, these observations are dropped.

${ }^{19}$ This NH was initially a for-profit institution and, consequently, changed the regulation regime. Since for-profit NHs provide luxury residential services, their production process is hardly comparable with the production process of other NHs.

${ }^{20}$ The reported number of $\mathrm{NHs}$ for each institutional form is the average number of homes over the whole period considered. The number of private-law NFP NHs ranges from 21 to 23 , while public-law NHs vary between 20 and 22 .
} 
size. The number of beds ranges from a minimum of 28 to a maximum of 162 , which leads to a high standard deviation also in the total annual resident days. Differences in case-mix characteristics are also remarkable: the average patient dependency index ranges from 0.8 to 3.8 , even though mean and median values are very close. As expected, the nursing staff ratio is close to 1 . In fact, NHs are supposed to follow the guidelines of the RDPH and to employ as many nurses as suggested. Large variations are observed for all input prices. The price of capital shows the greatest variation, mostly explained by investments made to renew the facility. The labor price shows the average yearly wage of the staff and varies between Sfr 63,000 and Sfr 94,000. The mean price for meals is Sfr 8.40 and ranges between Sfr 5 and Sfr 12. These reasonable values support our specification of material price. Labor costs represent $82 \%$ of total costs, whereas capital costs and material costs account for $6 \%$ and $12 \%$, respectively.

To focus on differences between private-law and public-law NHs, we calculate the mean and the standard deviation of the above variables separately for each subsample (see Table 3). In the last column of Table 3, we report the results of a two-sided $t$-test under the null hypothesis of equal means between the two groups. The statistics show that public-law and private-law NFP NHs are similar in many aspects, which also explains the similarity in observed mean costs per resident. NHs run under different organizational forms face similar residents and input prices. The only statistically significant difference is found in the average number of beds. Private-law and public-law NHs have, respectively, 59 and 77 beds on average, suggesting that public NHs have decreasing average costs. Regarding output characteristics, the two groups do not show significant differences either in the nursing staff ratio or in the case-mix. Although data do not show important differences between public-law and private-law NFP NHs, unobserved factors related to costs may still result in different performance. For example, $Q_{2}$ may capture only part of quality differences. Hence, NHs providing higher (unobserved) quality services may perform better, ceteris paribus. 


\subsection{Measuring the impact of the institutional form}

In this analysis we investigate structural and managerial differences between private-law and public-law NHs by means of SFA. These models estimate a benchmarking frontier against which the actual performance of the firms in the sample is compared. ${ }^{21}$ Our strategy to measure structural and managerial differences relies on the literature on exogenous factors in the analysis of efficiency and considers two approaches. ${ }^{22}$ The first approach relies on the assumption that the institutional form affects the degree of inefficiency directly, but not the production process. The underlying assumption is that performance differences are due to factors under control of the manager; for this reason they are interpreted as managerial differences (Coelli et al., 1999). In this case, the performance of each $\mathrm{NH}$ is measured in relation to a single best practice frontier and the inefficiency term is modeled as a function of exogenous factors. The second approach assumes that exogenous factors are not under control of the manager and therefore shift the production function up- or downward, leading to a direct impact on total costs. For this reason they are interpreted as structural differences. By including a dummy variable for the institutional form directly into the main cost equation, we allow for two distinct best practice frontiers. ${ }^{23}$

Which approach to use depends on the features of the sector under analysis, on the research question, and on the assumption of the estimation model. In the present analysis, we combine these approaches to simultaneously assess structural and managerial differences due to the institutional form, and apply the TRE model to take unobserved heterogeneity into account (Greene, 2005). Structural differences are interpreted as a shift of the production function and

\footnotetext{
${ }^{21}$ For an application of stochastic frontier models to health care institutions, see for instance Berta et al. (2010).

${ }^{22}$ The ideal situation to study differences due to the institutional form would be to compare institutions with the same ownership form but different institutional forms; i.e., governmentrun NHs versus NHs owned by the local government but run as foundation (public foundations). However, due to the small sample size of public foundation $\mathrm{NHs}(6.7 \%)$, we are not able to use this identification strategy.

${ }^{23} \mathrm{~A}$ similar approach has been applied in the literature on hospital efficiency in order to study the impact of ownership (Grosskopf and Valdmanis, 1987) and size (Ozcan at al., 1998), although not combined with a TRE model.
} 
measured by including a dummy variable in the deterministic part of the frontier. Managerial differences are investigated by using nonparametric tests on the mean inefficiency obtained from the TRE model, as in Farsi et al. (2008). We also model the time-varying inefficiency in the TRE model as a function of the institutional form. However, the results obtained with different softwares (NLOGIT and STATA) are not robust and we feel compelled to not use this approach, even though it is correct from an econometric point of view. ${ }^{24}$

We estimate TRE models with and without Mundlak correction and, for comparison purposes, we also run regressions without the institutional dummy variable in the deterministic part of the frontier. ${ }^{25}$ Consistent estimates of $\mathrm{RE}$ models rely on the assumption of no correlation between the individual effects and the covariates. This means that the inefficiency level is uncorrelated with input choices and output. As shown by Farsi et al. (2005), the Mundlak correction can be used in frontier models to address the bias deriving from this correlation. This correction is not used in Farsi et al. (2008). Instead, the fixed effects model allows for partial correlation (Cameron and Trivedi, 2010). However, due to the low within-variation of the covariates our estimates would be imprecise (Cameron and Trivedi, 2005; Clark and Linzer, 2014). Moreover, the fixed effects model does not allow us to estimate the coefficient of time-invariant factors, such as the institutional form. Note that stochastic frontier models are robust with respect to distributional assumptions of the error components when generating comparisons of group mean inefficiencies (Folland and Hofler, 2001).

\subsection{Results}

Table 4 reports the results of our two approaches (Model 1 and Model 2 estimated using NLOGIT Version 5). Model 1 estimates a single benchmarking frontier, while Model 2 includes the dummy for the institutional form in the

\footnotetext{
${ }^{24}$ Detailed information is available upon request.

${ }^{25}$ We use an ad-hoc Mundlak formulation which consists of including the mean values of those variables that lead to a rejection of the Hausman test. This approach was developed to save degree of freedom in the presence of small sample size. The p-value of the Hausman test after including the Mundlak correction is 0.0613 . The variables included are $\ln Q_{1}, \ln _{l}$, $\ln \mathrm{Yln}_{1}$, and $\ln \mathrm{Q}_{1} \ln \mathrm{Q}_{2}$.
} 
deterministic part of the frontier. Models $1 b$ and $2 b$ incorporate the Mundlak correction.

All the first-order coefficients are highly significant and positive, as well as some of the interaction terms which support the translog functional form. The estimated coefficients are very robust across the two model specifications. More severe patients are more costly to treat $\left(Q_{1}\right)$ and higher staffing levels also lead to higher costs. The coefficient of $Q_{1}$ loses significance when its mean is included in the Mundlak specification. This is due to the fact that the mean captures the majority of the variation. The Mundlak coefficients are all highly statistically significant, with significance levels between $1 \%$ and $5 \%$. A rising trend is observed in year dummy coefficients, which suggests that technological progress or unobserved factors (e.g. quality improvements) lead to higher costs each year.

The main result of interest is the effect of the institutional form. The effect of structural differences on costs is shown in Model 2. When we do not correct for correlated inefficiency, we do not find evidence of cost differences between publiclaw and private-law NHs. However, after correcting for the bias, the dummy is statistically significant at $1 \%$ level and shows that public-law NHs are more costly by $2 \%$. This finding is confirmed also with traditional regression models (Table 5), although the level of significance decreases at $10 \%{ }^{26}$

To investigate managerial differences across institutional forms, we apply the Kruskal-Wallis test on the estimated inefficiency scores, which are presented in Table 6 for all NHs, and separately for public-law and private-law organizations. Mean inefficiency is about 3\%, both for public-law and private-law NHs and across all model specifications, and reaches up to $17 \%$. The results from the Kruskal-Wallis test confirm that there are no systematic differences by institutional form in mean inefficiency (see Table 7). These results suggest that differences in costs across institutional forms are mainly due to structural differences rather than managerial performance.

\footnotetext{
${ }^{26}$ A model with ownership type (private vs. public) instead of institutional form was also considered. The results showed that ownership type does not affect total costs.
} 
In the last rows of Table 4 , we provide the estimated constant $\left(\delta_{0}\right)$, the standard deviation of the individual effects $\left(\sigma_{\alpha}\right)$, the standard deviation of the error term $(\sigma)$, and the ratio $(\lambda)$ between the standard deviation of the inefficiencies $\left(\sigma_{u}\right)$ and the standard deviation of the stochastic term $\left(\sigma_{v}\right)$. Note that all these components are highly significant. Since the value of $\lambda$ defines the relative contribution of the inefficiency term with respect to the stochastic term, a positive and statistically significant number supports the existence of the two error components. ${ }^{27}$ The difference in the $\lambda$ coefficient between the two models arises because of the different model specification.

Our results indicate that the Hessian matrix of the estimated cost functions with respect to input prices calculated at the approximation point is not negative semi-definite. Thus, the concavity condition is not satisfied in any of the specifications, meaning that firms' strategies are not responsive to changes in input factor prices. This can be explained by the fact that input choices in Swiss NHs are substantially limited by regulation (Filippini and Farsi, 2004). The interpretation of the estimated coefficients in Table 4 relies on the behavioral cost framework proposed by Bös (1986).

\section{Conclusions}

It has been suggested that the consumer surplus can be lower in the mixed (public and private) oligopoly than in private oligopoly when public firms are as efficient as private firms. However, the government may not privatize the public firm unless its efficiency is low enough as compared to private firms (BárcenaRuiz, 2012). To what extent do public NHs differ from private NFP NHs in terms of cost efficiency? Policy-makers in several European countries are currently debating the advantages of replacing public organizations with private organizations (e.g., foundations) for the care of elderly people. Restructuring

\footnotetext{
${ }^{27}$ We analyzed the skewness of the OLS residuals. As Waldman (1982) shows, when the OLS residuals are skewed in the "wrong" direction, the results from the maximum likelihood estimator are those of a simple OLS rather than a cost frontier. The normality test shows that our OLS residuals are right skewed (0.23) and the null hypothesis of normally distributed residuals can be rejected at $99 \%$ significance level. Therefore, our data and model specification support the adoption of stochastic frontier models.
} 
policies have shown their limitation as a viable strategy for controlling public health expenditure, at least in the hospital sector (Piacenza et al., 2010). Financial pressure on health care budgets is increasing, and little evidence is available on the performance of different types of NFP NHs.

Through this study, we investigated differences in cost efficiency between institutional forms of nursing home care using data from the Swiss canton of Ticino. Our main purpose was to disentangle differences in cost efficiency due to structural (time-invariant) aspects from managerial (time-varying) aspects, which is generally neglected in the related literature. To this end, we first estimated a cost frontier based on a TRE model. This empirical strategy performs well in the presence of latent heterogeneity and time-varying inefficiency. However, the fact that structural differences are captured by the individual effects may be a limitation. Therefore, we proposed an alternative empirical strategy by accounting for the institutional form in the deterministic part of the cost frontier. We believe this is a valid approach to assess the impact of organizational characteristics on the performance of NHs in the presence of unobserved heterogeneity.

We found that structural differences lead to higher costs of public-law NHs as compared to private-law NHs. However, these cost differences are relatively small. Moreover, this may be due to the fact that public-law NHs face more political constraints than private-law NHs because the political system attaches a value to factors such as governance procedures, location and choice of residents. Conversely, we found no evidence of systematic managerial differences between public-law and private-law NHs. One possible explanation for this result is the extensive regulation that affects all NHs in the region. Since costs are tightly controlled by the regulator, little room is left for management discretion. Another explanation may be that private nonprofit and public NHs face similar constraints. Foundation councils set restrictions on the decision-making power of their managers like in public NHs. Finally, relatively small cost differences may be due to unobserved quality differences between public and private NHs.

From a policy point of view, our results suggest that promoting private NFP 
NHs tends to reduce the costs for elderly care, although the reduction is quite small. From an empirical point of view, our findings show the importance of testing for both structural and managerial differences in costs between institutional forms. Because of data availability, our study was limited to a short period of time (5 years). Therefore, changes in efficiency that may require a longer time to occur are not captured. Further research using longer datasets is needed to disentangle more precisely the differences in structural and managerial costs across organizational forms of long-term care. Finally, our findings cannot be easily generalized to other regions since they may not reflect structural and managerial cost differences in other regulatory settings. 


\section{Acknowledgments}

Earlier drafts of this work were presented at the XII European Workshop on Efficiency and Productivity Analysis (Verona, June 2011) and the 8th World Congress on Health Economics (Toronto, July 2011). We are grateful to the participants of these conferences, Andrew Street, two anonymous reviewers and the associated editor for their helpful comments and suggestions. Any error is the fault of the authors. 


\section{References}

Aigner, D., Lovell, C., Schmidt, P., 1977. Formulation and estimation of stochastic frontier production function models. Journal of Econometrics, 6, 21-37.

Bárcena-Ruiz, J.C., 2012. Privatization when the public firm is as efficient as private firms, Economic Modelling, 29(4), 1019-1023.

Battese, G.E., Coelli, T.J., 1992. Frontier production functions, technical efficiency and panel data: With application to paddy farmers in India. Journal of Productivity Analysis, 3, 153-169.

Berta, P., Callea, G., Martini, G., Vittadini, G., 2010. The effects of upcoding, cream skimming and readmissions on the Italian hospitals efficiency: A population-based investigation. Economic Modelling, 27, 812-821.

Birnbaum, H., Bishop, C., Lee, A., Jensen, G., 1981. Why do nursing home costs vary? The determinants of nursing home costs. Medical Care, 19, 1095-1107.

Bös, D., 1986. Public enterprise economics. Amsterdam: North-Holland.

Bostick, J.E., Rantz, M.J., Flesner, M.K., Riggs, C.J., 2006. Systematic review of studies of staffing and quality in nursing homes. Journal of the American Medical Directors Association, 7(6), 366-376.

Cameron, A.C., Trivedi, P.K., 2005. Microeconometrics. Methods and applications. New York: Cambridge University Press.

Cameron, A.C., Trivedi, P.K., 2010. Microeconometrics using Stata. Revised edition. Texas: Stata Press

Castiglione, C., Infante, D., 2014. ICTs and time-span in technical efficiency gains. A stochastic frontier approach over a panel of Italian manufacturing firms. Economic Modelling, 41, 55-65.

Charoenrat, T., Harvie, C., 2014. The efficiency of SMEs in Thai manufacturing: A stochastic frontier analysis. Economic Modelling, 43, 372-393.

Chou, S., 2002. Asymmetric information, ownership and quality of care: an empirical anaysis of nursing homes. Journal of Health Economics, 21, 293-311.

Clark, T.S., Linzer, D.A., 2014. Should I use fixed or random effects? Political Science Research and Methods, 3(2), 399-408. 
Coelli, T., Perelman, S., Romano, E., 1999. Accounting for environmental influences in stochastic frontier models: with application to international airlines. Journal of Productivity Analysis, 11, 251-273.

Colombi, R., Kumbhakar, S., Martini, G., Vittadini, G., 2014. Closed-skew normality in stochastic frontiers with individual effects and long/short-run efficiency. Journal of Productivity Analysis, 42(2), 123-136.

Cornwell, C., Schmidt, P., Sickles, R., 1990. Production frontiers with cross-sectional and time-series variation in efficiency levels. Journal of Econometrics, 46, 185-200.

Crivelli, L., Filippini, M., Lunati, D., 2002. Regulation, ownership and efficiency in the Swiss nursing home industry. International Journal of Health Care Finance and Economics, 2, 79-97.

Danquah, M., Ouattara, B., 2015. What drives national efficiency in sub-Saharan Africa, Economic Modelling, 44, 171-179.

Di Giorgio, L., Filippini, M., Masiero, G., 2014. Implications of global budget payment system on nursing home costs. Health Policy, 115, 237-248.

Evans, R., 1971. "Behavioural" cost functions for hospitals. The Canadian Journal of Economics, 4, 198-215.

Farsi, M., Filippini, M., 2004. An empirical analysis of cost efficiency in non-profit and public nursing homes. Annals of Public and Cooperative Economics, 75(3), 339-365.

Farsi, M., Filippini, M., Kuenzle, M., 2005. Unobserved heterogeneity in stochastic cost frontier models: an application to Swiss nursing homes. Applied Economics, 37, 2127-2141.

Farsi, M., Filippini, M., Lunati, D., 2008. Economies of scale and efficiency measurement in Switzerland's nursing homes. Swiss Journal of Economics and Statistics, 144, $359-378$.

Filippini, M., 1996. Economies of scale and utilization in the Swiss electric power distribution industry. Applied Economics, 28, 543-550.

Filippini, M., Greene, W., 2015. Persistent and transient productive inefficiency: a maximum simulated likelihood approach. Journal of Productivity Analysis, DOI 10.1007/ s11123-015-0446-y.

Folland, S.T., Hofler, R.A., 2001. How reliable are hospital inefficiency estimates? 
Exploiting the dual to homothetic production. Health Economics, 10(8), 683-698.

Grabowski, D.C., Huskamp, H. A., Stevenson, D.G., Keating, N.L., 2009. Ownership status and home health care performance. Journal of Aging \& Social Policy, 21(2), $130-143$.

Grabowski, D.C., Feng, Z., Hirth, R., Rahman, M., Mor, V., 2013. Effect of nursing home ownership on the quality of post-acute care: an instrumental variables approach. Journal of Health Economics, 32, 12-21.

Greene, W., 2005. Reconsidering heterogeneity in panel data estimators of stochastic frontier model. Journal of Econometrics, 126, 269-303.

Greene, W., 2010. A stochastic frontier model with correction for sample selection. Journal of Productivity Analysis, 34, 15-24.

Grosskopf, S., Valdmanis, V., 1987. Measuring hospital performance. A non-parametric approach. Journal of Health Economics, 6, 89-107.

Hart, O., Schleifer, A., Vishny, R., 1997. The proper scope of government: theory and an application to prisons. The Quarterly Journal of Economics, 112, 1127-1161.

Haskel, J., Sanchis, A., 1995. Privatization and X-inefficiency: a bargaining approach. The Journal of Industrial Economics, 43, 301-321.

Hillmer, M.P., Wodchis, W.P., Gill, S.S., Anderson, G.M., Rochon, P.A., 2005. Nursing home profit status and quality of care: is there any evidence of association? Medical Care Research and Review, 62(2), 139-166.

Holmes, J., 1996. The effects of ownership and ownership change on nursing home industry costs. Health Services Research, 31, 327-46.

Kapur, K., Weisbrod, B., 2000. The roles of government and nonprofit suppliers in mixed industries. Public Finance Review, 28, 275-308.

Knox, K.J., Blankmeyer, E.C., Stutzman, J.R., 2002. Organizational efficiency and quality in Texas nursing facilities. Health Care Management Science, 6, 175-188.

Kumbhakar, S.C., Lovell, C.A.K., 2003. Stochastic Frontier Analysis. Cambridge University Press.

Murillo-Zamorano, L.R., 2004. Economic efficiency and frontier techniques. Journal of Economic surveys, 18(1), 33-77.

O'Neill, C., Harrington, C., Kitchener, M., Saliba, D., 2003. Quality of care in nursing 
homes: an analysis of relationships among profit, quality, and ownership. Medical Care, 41(12), 1318-1330.

Ozcan, Y., Wogen, S., Mau, L., 1998. Efficiency evaluation of skilled nursing facilities. Journal of Medical Systems, 22, 211-224.

Piacenza, M., Turati, G., Vannoni, D., 2010. Restructuring hospital industry to control public health care expenditure: The role of input substitutability. Economic Modelling, $27(4), 881-890$.

Pitt, M., Lee, L., 1981. The measurement and sources of technical inefficiency in Indonesian weaving industry, Journal of Development Economics, 9, 43-64.

Rose-Ackerman, S., 1996. Altruism, nonprofits, and economic theory. Journal of Economic Literature, 34, 701-728.

Santerre, R.E., Vernon, J.A., 2007. Ownership form and consumer welfare: evidence from the nursing home industry. Inquiry 44, 381-399.

Rosenbaum, D.I., Lamphear, C.F., Rebeck, K., 2001. The effects of acuity and utilization on nursing home costs. Review of Industrial Organization, 19(3), 279-294.

Schlesinger, M., Gray, BH., 2006. How nonprofits matter in American medicine, and what to do about it. Health Affairs, 25(4), W287-W303.

Schmidt, P., Sickles, R., 1984. Production frontiers and panel data. Journal of Business and Economic Statistics, 2, 367-374.

Sickles, R.C., 2005. Panel estimators and the identification of firm-specific efficiency levels in parametric, semiparametric and nonparametric settings. Journal of Econometrics, 126(2), 305-334.

Vitaliano, D., Toren, M., 1994. Cost and efficiency in nursing homes: a stochastic frontier approach. Journal of Health Economics, 13, 281-300.

Waldman, D., 1982. A stationary point for the stochastic frontier likelihood. Journal of Econometrics, 18, 275-279.

Wilson, J., 1989. Bureaucracy: what government agencies do and why they do it. Washington DC: Basic Books. 


\begin{tabular}{lcc}
\hline & TRE & TRE with Mundlak formulation \\
\hline Firm-specific component $\alpha_{i}$ & $i i d\left(0, \sigma_{\alpha}^{2}\right)$ & $\alpha_{i}=\gamma \bar{X}_{i}+\delta_{i}$ \\
& & $\bar{X}_{i}=\frac{1}{T} \sum_{t=1}^{T} X_{i t}$ \\
& & $\delta_{i} \sim i i d\left(0, \sigma_{\delta}^{2}\right)$ \\
\hline Random error $\varepsilon_{i t}$ & $\varepsilon_{i t}=v_{i t}+u_{i t}$ & $\varepsilon_{i t}+u_{i t}$ \\
& $u_{i t} \sim N^{+}\left(0, \sigma_{u}^{2}\right)$ & $u_{i t} \sim N^{+}\left(0, \sigma_{u}^{2}\right)$ \\
$v_{i t} \sim N\left(0, \sigma_{v}^{2}\right)$ & $v_{i t} \sim N\left(0, \sigma_{v}^{2}\right)$ \\
\hline Inefficiency & $E\left[u_{i t} \mid u_{i t}+v_{i t}\right]$ & $E\left[u_{i t} \mid u_{i t}+v_{i t}\right]$ \\
\hline
\end{tabular}

Table 1: Econometric specifications of TRE models.

\begin{tabular}{lccccc}
\hline Variables & Mean & Std. Dev. & Median & Min & Max \\
\hline Average cost (Sfr/resident day) & 232.80 & 26.40 & 235.50 & 172.85 & 297.60 \\
Total annual resident days $(Y)$ & 24032 & 9780 & 21911 & 9925 & 58324 \\
Average dependency index $\left(Q_{1}\right)$ & 3.08 & 0.37 & 3.14 & 0.80 & 3.80 \\
Nursing staff ratio $\left(Q_{2}\right)$ & 0.966 & 0.090 & 0.96 & 0.74 & 1.55 \\
Average labor price in Sfr per employee $\left(P_{l}\right)$ & 80266 & 4817 & 80613 & 63363 & 93704 \\
Average capital price in Sfr per bed $\left(P_{k}\right)$ & 5398 & 2671 & 4993 & 1054 & 22891 \\
Average material price in Sfr per meal $\left(P_{m}\right)$ & 8.35 & 1.20 & 8.32 & 5.15 & 11.70 \\
Number of beds & 68 & 27.4 & 64 & 28 & 162 \\
\hline
\end{tabular}

Notes: All monetary values are in 2005 Swiss francs (Sfr), adjusted by the national Consumer Price Index.

Table 2: Descriptive statistics of the main costs and input variables (210 observations). 


\begin{tabular}{|c|c|c|c|c|c|}
\hline & \multicolumn{2}{|c|}{ Private-law NHs } & \multicolumn{2}{|c|}{ Public-law NHs } & t-test \\
\hline Variables & Mean & Std. Dev. & Mean & Std. Dev. & \\
\hline Average cost (Sfr/resident day) & 233.90 & 29.55 & 231.60 & 22.70 & 0.650 \\
\hline Total annual resident days $(Y)$ & 20755.80 & 7252.45 & 27464.80 & 10882.70 & $-5.342^{* * *}$ \\
\hline Average dependency index $\left(Q_{1}\right)$ & 3.104 & 0.369 & 3.071 & 0.371 & 0.659 \\
\hline Nursing staff ratio $\left(Q_{2}\right)$ & 0.969 & 0.111 & 0.963 & 0.062 & 0.512 \\
\hline $\begin{array}{l}\text { Average labor price in Sfr per } \\
\text { employee }\left(P_{l}\right)\end{array}$ & 80068.70 & 4987.40 & 80474.05 & 4647.10 & -0.616 \\
\hline $\begin{array}{l}\text { Average capital price in } \mathrm{Sfr} \\
\text { per bed }\left(P_{k}\right)\end{array}$ & 5451.20 & 3369.30 & 5342.25 & 1665.50 & 0.298 \\
\hline $\begin{array}{l}\text { Average material price in Sfr } \\
\text { per meal }\left(P_{m}\right)\end{array}$ & 8.20 & 1.25 & 8.50 & 1.13 & -1.630 \\
\hline Number of beds & 59 & 21 & 77 & 30 & $-5.111^{* * *}$ \\
\hline Number of homes & 22 & & 21 & & - \\
\hline Number of observations & 107 & & 103 & & - \\
\hline
\end{tabular}

Notes: All monetary values are in 2005 Swiss francs (Sfr), adjusted by the national Consumer Price Index. Significance levels: ${ }^{*}=10 \%,{ }^{* *}=5 \%,{ }^{* * *}=1 \%$.

Table 3: Differences in mean costs and inputs among institutional forms. 


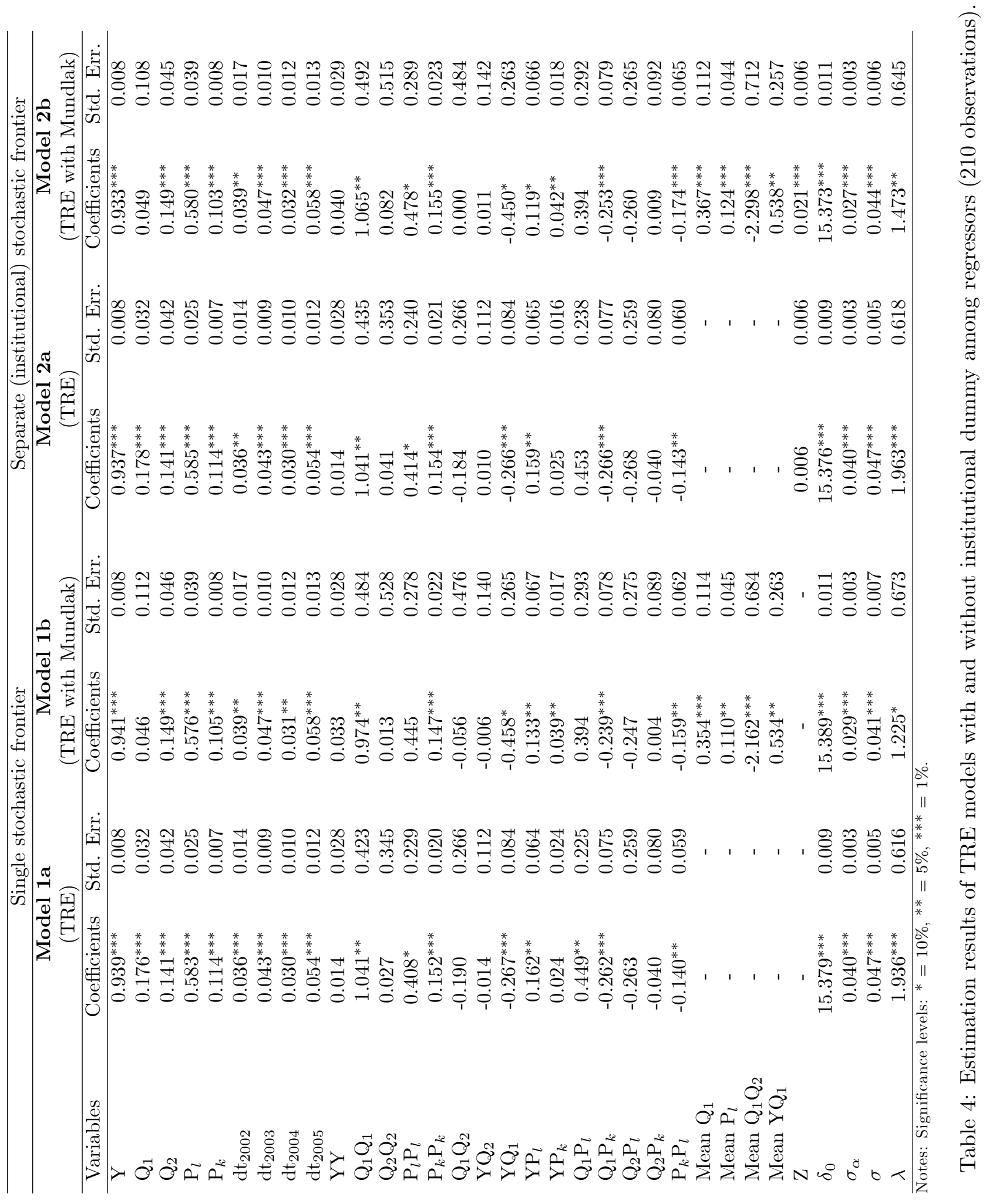




\begin{tabular}{|c|c|c|c|c|}
\hline & \multicolumn{2}{|c|}{ Random effects model } & \multicolumn{2}{|c|}{ RE model with Mundlak } \\
\hline Variables & Coefficients & Std.Err. & Coefficients & Std. Err. \\
\hline $\mathrm{Y}$ & $0.942^{* * *}$ & 0.017 & $0.936^{* * *}$ & 0.014 \\
\hline $\mathrm{Q}_{1}$ & $0.184^{* * *}$ & 0.054 & 0.044 & 0.072 \\
\hline $\mathrm{Q}_{2}$ & $0.149^{* * *}$ & 0.051 & $0.150^{* * *}$ & 0.050 \\
\hline $\mathrm{P}_{l}$ & $0.580^{* * *}$ & 0.035 & $0.576^{* * *}$ & 0.039 \\
\hline $\mathrm{P}_{k}$ & $0.114^{* * *}$ & 0.010 & $0.101^{* * *}$ & 0.010 \\
\hline $\mathrm{dt}_{2002}$ & $0.036^{* * *}$ & 0.009 & $0.039^{* * *}$ & 0.009 \\
\hline $\mathrm{dt}_{2003}$ & $0.046^{* * *}$ & 0.009 & $0.049^{* * *}$ & 0.010 \\
\hline $\mathrm{dt}_{2004}$ & $0.031^{* * *}$ & 0.009 & $0.033^{* * *}$ & 0.009 \\
\hline $\mathrm{dt}_{2005}$ & $0.056^{* * *}$ & 0.010 & $0.059^{* * *}$ & 0.010 \\
\hline YY & -0.018 & 0.060 & 0.024 & 0.052 \\
\hline $\mathrm{Q}_{1} \mathrm{Q}_{1}$ & $1.094^{* *}$ & 0.511 & $1.105^{* *}$ & 0.507 \\
\hline $\mathrm{Q}_{2} \mathrm{Q}_{2}$ & -0.006 & 0.311 & 0.064 & 0.309 \\
\hline $\mathrm{P}_{l} \mathrm{P}_{l}$ & $0.406^{*}$ & 0.238 & $0.522^{* *}$ & 0.238 \\
\hline $\mathrm{P}_{k} \mathrm{P}_{k}$ & $0.164^{* * *}$ & 0.030 & $0.161^{* * *}$ & 0.029 \\
\hline $\mathrm{Q}_{1} \mathrm{Q}_{2}$ & -0.339 & 0.267 & -0.069 & 0.277 \\
\hline $\mathrm{YQ}_{2}$ & 0.007 & 0.117 & 0.009 & 0.115 \\
\hline $\mathrm{YQ}_{1}$ & $-0.283^{* *}$ & 0.119 & $-0.506^{* * *}$ & 0.140 \\
\hline $\mathrm{YP}_{l}$ & $0.160^{* *}$ & 0.075 & 0.111 & 0.072 \\
\hline $\mathrm{YP}_{k}$ & 0.030 & 0.026 & $0.049^{* *}$ & 0.024 \\
\hline $\mathrm{Q}_{1} \mathrm{P}_{l}$ & $0.545^{* *}$ & 0.237 & $0.442^{*}$ & 0.231 \\
\hline $\mathrm{Q}_{1} \mathrm{P}_{k}$ & $-0.285^{* * *}$ & 0.091 & $-0.247^{* * *}$ & 0.087 \\
\hline $\mathrm{Q}_{2} \mathrm{P}_{l}$ & -0.284 & 0.207 & -0.280 & 0.204 \\
\hline $\mathrm{Q}_{2} \mathrm{P}_{k}$ & -0.043 & 0.081 & 0.021 & 0.081 \\
\hline $\mathrm{P}_{k} \mathrm{P}_{l}$ & $-0.166^{* *}$ & 0.076 & $-0.198^{* * *}$ & 0.074 \\
\hline Mean $Q_{1}$ & - & - & $0.367^{* * *}$ & 0.077 \\
\hline Mean $\mathrm{P}_{l}$ & - & - & $0.132^{* *}$ & 0.057 \\
\hline Mean $\mathrm{Q}_{1} \mathrm{Q}_{2}$ & - & - & $-2.544^{* * *}$ & 0.546 \\
\hline Mean $\mathrm{YQ}_{1}$ & - & - & $0.553^{* * *}$ & 0.182 \\
\hline Z & 0.004 & 0.013 & $0.018^{*}$ & 0.011 \\
\hline$\delta_{0}$ & $15.411^{* * *}$ & 0.013 & $15.402^{* * *}$ & 0.012 \\
\hline $\mathrm{R}^{2}$ & 0.982 & & 0.988 & \\
\hline
\end{tabular}

Table 5: Results of the non-frontier models RE and RE Mundlak (210 observations). 


\begin{tabular}{lcccc}
\hline MEAN MANAGERIAL INEFFICIENCY & Mean & Std. Dev. & Min & Max \\
\hline All NHs (N=210) & & & & \\
Model 1a & 0.0324 & 0.0191 & 0.0087 & 0.1647 \\
Model 1b & 0.0251 & 0.0113 & 0.0083 & 0.0972 \\
Model 2a & 0.0326 & 0.0193 & 0.0086 & 0.1671 \\
Model 2b & 0.0281 & 0.0143 & 0.0086 & 0.1193 \\
Private-law NHs (N=107) & & & \\
Model 1a & 0.0333 & 0.0224 & 0.0088 & 0.1647 \\
Model 1b & 0.0253 & 0.0131 & 0.0083 & 0.0972 \\
Model 2a & 0.0337 & 0.0228 & 0.0089 & 0.1671 \\
Model 2b & 0.0291 & 0.0168 & 0.0086 & 0.1192 \\
Public-law NHs (N=103) & & & & \\
Model 1a & 0.0315 & 0.0149 & 0.0087 & 0.0709 \\
Model 1b & 0.0250 & 0.0090 & 0.0097 & 0.0500 \\
Model 2a & 0.0316 & 0.0150 & 0.0086 & 0.0712 \\
Model 2b & 0.0271 & 0.0110 & 0.0093 & 0.0587 \\
\hline
\end{tabular}

Table 6: Mean managerial inefficiency of public-law and private-law NHs.

\begin{tabular}{ccccc}
\hline $\begin{array}{l}\text { Kruskal-Wallis test on equality of mean } \\
\text { managerial inefficiency between groups }\end{array}$ & \multicolumn{2}{c}{$\begin{array}{c}\text { Single stochastic } \\
\text { frontier }\end{array}$} & \multicolumn{2}{c}{$\begin{array}{c}\text { Separate (institutional) } \\
\text { stochastic frontier }\end{array}$} \\
\hline & Model 1a & Model 1b & Model 2a & Model 2b \\
\hline$p$-value & 0.8211 & 0.5269 & 0.9685 & 0.8018 \\
\hline
\end{tabular}

Table 7: Results of the Kruskal-Wallis test on the equality of mean managerial inefficiency between public-law and private-law NHs. 